ever, acquiring an Ethiopian-born certificate would raise the question of whether the individual shall be compensated as an Ethiopian or as a foreigner-in foreign or in local currency. Foreigners in Ethiopian higher education get paid at least five times as much as Ethiopian academics and receive their salaries in foreign currency. The absence of clarity on this issue has caused controversies.

In sum, the current wave of motivation and reforms create together a conducive environment to significantly scale up diaspora engagement in the knowledge sector. Not to lose momentum, swift strategic measures are needed to tap into its appealing potential.

\section{China's English-Language Journals in Human and Social Sciences}

\author{
Mengyang Li and Rui Yang
}

Mengyang $\mathrm{Li}$ is a PhD candidate and Rui Yang is professor in the Faculty of Education at the University of Hong Kong. E-mails: u3003515@ connect.hku.hk and yangrui@hku.hk.

$\mathrm{C}$ hina has made some remarkable achievements in higher education during the past few decades. However, Chinese researchers in the humanities and social sciences (HSS) have achieved far less visibility within the international community than their peers in science, technology, and medicine (STM). The government recently stressed the significance of further internationalizing Chinese HSS in teaching, research, and in terms of sociocultural impact. Developing English-language academic journals is one of China's proactive initiatives to stimulate its HSS to go global. Based on face-to-face research interviews with 32 journal editors and on a thorough review of related policy documents at various levels conducted during 20I7-20I8, this article reports some of the main findings of an investigation on the current state of HSS English-language journals on the Chinese mainland.

\section{A National Scenario}

By 2018, China had 66 HSS English-language academic journals, primarily hosted by the Chinese Academy of Social Sciences, higher education institutions, and publishers. Compared with over 400 STM English-language journals and more than 2,000 HSS journals in Chinese language published in China, this is a modest figure.
These 66 journals cover a variety of academic subject areas, mostly in business and economics (I7.26 percent), followed by eight (I2 percent) in law, six (9 percent) in social sciences, four ( 6 percent) in education, and three $(5$ percent) in history. Thirty-seven (56 percent) have "China" or "Chinese" in their titles. While the earliest, the Chinese Journal of Applied Linguistics, was established in 1978, most of the journals were launched during the past two decades. Sixty (9I percent) were launched after 2000, 52 (79 percent) after 2006, and 34 (52 percent) after 20I0. Many were established to answer the central government's policy calls for HSS to "go out," aiming at improving the international visibility of Chinese social research.

So far, the international impact of these journals has been extremely limited. Only six are indexed by the Social Sciences Citation Index (SSCI) and none by the Arts \& Humanities Citation Index (A\&HCI). Twenty-seven (4I percent) are indexed in Scopus (Elsevier's abstract and citation database launched in 2004). In 2018, in the SCImago Journal Rank (based on Scopus data with a scale of four quartiles), only three of the journals were ranked in the first quartile in their respective areas, while II were ranked in the second, three in the third, and Io in the fourth. The underperformance of China's HSS English-language journals is due to a number of domestic and international factors.

\section{Disadvantages Due to International Knowledge ASYMMETRIES}

The humanities and social sciences, as institutionalized in universities throughout the world, are European in structure, organization, and concept. The American influence is particularly strong. Although increasing deterritorialized global flows are opening up possibilities for a pluralization of research imaginaries, the global structure of knowledge production is still largely hierarchical. The main disadvantages for HSS development in non-Western societies include the dominance of English, highly centralized means of knowledge dissemination-as demonstrated by international journals and publishers in global academic centers-and academic dependency on Western scholarship for ideas, theories, and methods.

Most editors report English as a major obstacle for their journals. They mention repeatedly that Chinese scholars, especially senior ones and to a lesser extent young domestic scholars and returnees, still do not have a satisfactory English writing ability. A large proportion of submissions from Chinese researchers are thus desk rejected. Further, the journals are hindered by their unfavorable positions in research evaluation systems. As rankings and league tables have become part of the global governance of higher education, China's domestic research evaluation system is 
increasingly shaped by the Science Citation Index (SCI), SSCI, and A\&HCI. Since the overwhelming majority of the HSS English-language journals are not indexed, it has been very difficult for them to attract international and domestic submissions.

The journals have encountered immense challenges in their attempt to internationalize. Only a small proportion have developed a fair understanding of what an international journal looks like and how to operate accordingly. In order to be better accessed internationally, 47 (7I percent) cooperate with international (Western) publishers, II (I7 percent) with Taylor \& Francis Group, nine (I4 percent) with Brill, and eight (i2 percent) with Springer. While several editors acknowledge the brand effect brought by international publishers, most say that even after years of partnership, the quality and impact of their journals have rarely improved. Some even worry about the financial pressure caused by the high cost of the partnership and its possible impact on the sustainability of their journals.

\section{Most editors report English as a major obstacle for their journals.}

\section{Dilem Mas between Local and INTERNATIONAL COMMITMENTS}

All the HSS English-language journals with relatively higher achievements in international visibility are struggling to strike a balance between international ambition and local commitment. The editors demonstrate a clear awareness of the Western, especially Anglo-American, hegemony in global knowledge production. They report a lack of understanding of - and even misunderstandings about-China and China's social research in international academia. The journals are therefore perceived as a platform for bringing Chinese scholarship to the outside world and facilitating multiple perspectives and mutual understanding in global HSS research.

However, hoping to be better recognized internationally, most of them make great efforts to include international scholars among their editorial board members, reviewers, and authors. The intention to have a larger international readership is desperate. Although many respondents are concerned about "overinternationalization" and "losing academic relevance to local society and autonomy," most journals in the social sciences set entry into SSCI as their current strategic goal. While SSCI and A\&HCI are not des- ignated as major targets in the humanities, the journals in these disciplines seek in a similar way to orient themselves toward the "golden standards" set by Western practices in order to enhance their international recognition.

Editors confirm the lingering difficulties in the dialogue between Chinese and Western scholarship. As an editor at Frontiers of Philosophy in China expressed, "We've translated and published articles written by leading Chinese scholars, but they have almost zero download, much lower than those written by younger Chinese diaspora members." This reflects the global position of China's HSS research. Issues such as lack of original theoretical contributions, catch-up mentality, overpragmatism, and academic nationalism have exerted a combined impact on HSS research in China, leading to a limited contribution to the dialogue with international scholars.

\section{Conclusion}

Confronted with challenges and dilemmas, China's HSS English-language journals are still at a preliminary stage of development. With strong support from the state, institutions, and individuals, they are well positioned to contribute to the dialogue between Chinese and international HSS scholars. As the wider contexts change locally and globally, they are required to adjust their agendas and priorities, and recontextualize their themes, concepts, and paradigms. Such adjustment takes time. More fundamentally, they need to balance realistic strategies to enhance international impact with orientation to Western research agendas and their long-term commitment to empowering Chinese HSS researchers to become global.

\section{World-Class Universities and Institutional Autonomy in China}

\section{Chelsea Blackburn Cohen}

Chelsea Blackburn Cohen is senior program officer, North America, for Scholarsat Risk.E-mail: chelseablackburncohen@nyu.edu.

This article is based on a Scholars at Risk's report entitled Obstacles to Excellence: Academic Freedom and China's Quest for World-Class Universities, available on SAR's website at https://www.scholarsatrisk.org/.

nce a hallmark of the higher education competition phenomenon of the twenty-first century, the 